\title{
Clear cell adenocarcinoma of the Cervix in a ten-year-old girl Without prenatal DIETHYLSTILBESTROL EXPOSURE
}

Singapore Med J 2016; 57(8): 470 doi: 10.11622/smedj.2016138

Dear Sir,

Cervical clear cell adenocarcinoma (CCAC) accounts for 3\%-10\% of adenocarcinoma of the uterine cervix cases ${ }^{(1,2)}$ and is often associated with diethylstilbestrol (DES) exposure in utero. ${ }^{(3)}$ CCAC of the uterine cervix is uncommon in adolescents and only a few such cases have been reported..$^{(1,4)}$

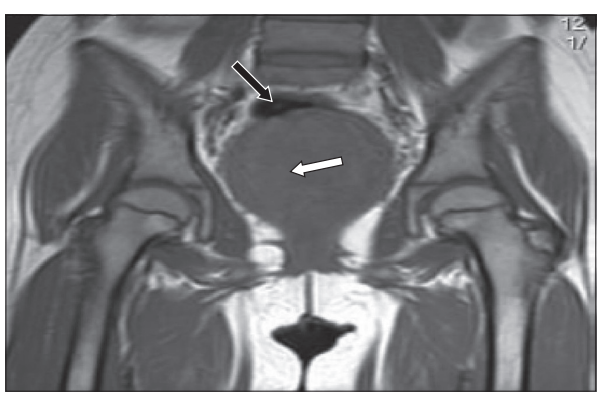

Fig. $1 \mathrm{MR}$ image of the pelvis shows the mass on the cervix (white arrow) at the uterus (black arrow).

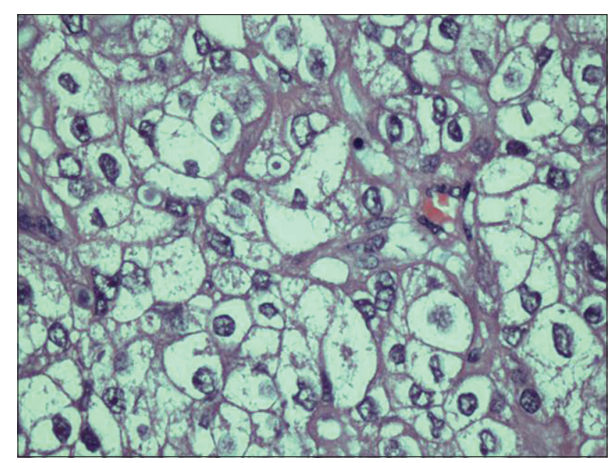

Fig. 2 Photomicrograph shows clear cell carcinoma (Haematoxylin \& eosin, $\times 400)$.
We herein report an extremely rare case of a patient with cervical CCAC without DES exposure. A ten-year-old girl presented with a history of intermittent bloodstained discharge of one year. She was only referred to a gynaecologist after a failure to respond to hormone therapy within one year. Physical examination revealed a palpable pelvic mass that was about the size of a gravid uterus of 14 weeks, with visible tissue protruding through the introitus. Magnetic resonance imaging showed a huge mass arising from the cervix of a rudimentary uterus and pushing the pelvic organs toward the abdomen (Fig. 1). There was no evidence of organomegaly or enlarged lymph nodes. The upper and lower urinary tracts appeared normal. Biopsy confirmed the diagnosis of Stage IB2 CCAC of the uterine cervix (Fig. 2). The patient underwent radical abdominal hysterectomy and bilateral pelvic lymph node dissection, followed by six cycles of carboplatin and paclitaxel. Subsequently, pelvic examination under anaesthesia, vault cytology and computed tomography of the abdomen and pelvis were performed. Unfortunately, the patient developed recurrence in her lungs and brain. She and her family declined further treatment and the patient succumbed three months later.

Previous literature showed that the first peak of CCAC occurs in women aged 17-37 years, while the second peak occurs in women aged 44-88 years. The former group comprised mostly DES-exposed women and the latter those without a history of DES exposure. ${ }^{(3,4)}$ Significant features for the prognosis of CCAC of the uterine cervix are related to the stage at diagnosis, tumour size, grade of nuclear atypia, pelvic lymph node status and lymphatic invasion. ${ }^{(3,5)}$ The key modality of treatment for early-stage cervical carcinoma is radical abdominal hysterectomy with pelvic lymphadenectomy, which results in permanent infertility in the patient. When CCAC of the uterine cervix occurs in adolescents and women of reproductive age, other surgical options should be considered if the patient desires to maintain her fertility after treatment.

We suggest that an awareness of rare, forgotten cancers (e.g. CCAC of the uterine cervix in adolescents) and the need for prompt referral to a tertiary gynaecological oncology centre should be raised among general practitioners, gynaecologists and surgeons. Additionally, CCAC of the uterine cervix in adolescents should be considered as a possible differential diagnosis of bloodstained vaginal discharge without a history of sexual abuse or DES exposure. In the interim, specialists and physicians should remain cautious and attempt to act early, assertively and properly to diagnose and treat CCAC of the uterine cervix in adolescents so as to improve the survival rate of patients.

Yours sincerely,

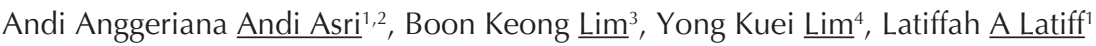

${ }^{1}$ Cancer Resource and Education Centre, ${ }^{2}$ Department of Obstetrics and Gynaecology, Faculty of Medicine and Health Sciences, Universiti Putra Malaysia, Selangor, ${ }^{3}$ Department of Obstetrics and Gynaecology, Faculty of Medicine, University of Malaya, Kuala Lumpur, Malaysia, ${ }^{4}$ Department of Gynaecological Oncology, KK Women's and Children's Hospital, Singapore. aanggeriana@yahoo.com.sg

\section{References}

1. Hanselaar A, van Loosbroek M, Schuurbiers O, et al. Clear cell adenocarcinoma of the vagina and cervix. An update of the central Netherlands registry showing twin age incidence peaks. Cancer 1997; 79:2229-36.

2. Smith EK, White MC, Weir HK, Peipins LA, Thompson TD. Higher incidence of clear cell adenocarcinoma of the cervix and vagina among women born between 1947 and 1971 in the United States. Cancer Causes Control 2012; 23:207-11.

3. Hanselaar AG, Van Leusen ND, De Wilde PC, Vooijs GP. Clear cell adenocarcinoma of the vagina and cervix. A report of the Central Netherlands Registry with emphasis on early detection and prognosis. Cancer 1991; 67:1971-8.

4. Yabushita H, Kanyama K, Sekiya R, Noguchi M, Wakatsuki A. Clear-cell adenocarcinoma of the uterine cervix in a 17-year-old adolescent. Int J Clin Oncol 2008; 13:552-4.

5. Reich O, Tamussino K, Lahousen M, et al. Clear cell carcinoma of the uterine cervix: pathology and prognosis in surgically treated stage IB-IIB disease in women not exposed in utero to diethylstilbestrol. Gynecol Oncol 2000; 76:331-5. 